\title{
A Review of the Literature on Fuel Poverty with a Focus on Ireland
}

\section{Graeme O’Meara}

\section{Social Indicators Research}

An International and Interdisciplinary Journal for Quality-of-Life Measurement

ISSN 0303-8300

Soc Indic Res

DOI 10.1007/s11205-015-1031-5

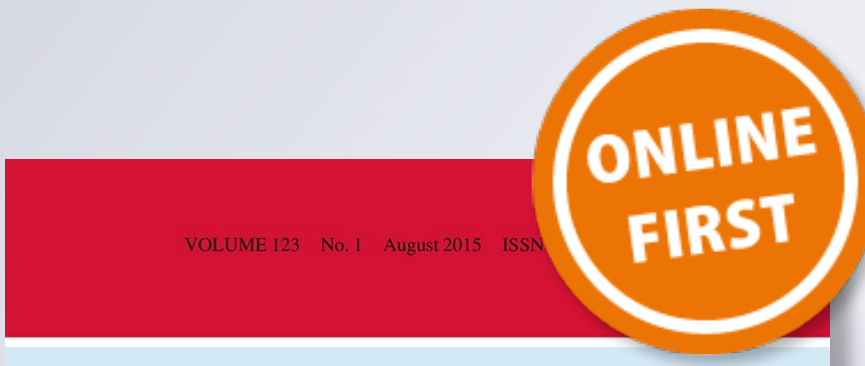

SOC I A L INDICA T ORS R ES E A R C H

AN INTERNATIONAL AND

INTERDISCIPLINARY JOURNAL

FOR QUALITY-OF-LIFE MEASUREMENT

Editor: Filomena Maggino

\section{블 Springer}


Your article is protected by copyright and all rights are held exclusively by Springer Science +Business Media Dordrecht. This e-offprint is for personal use only and shall not be selfarchived in electronic repositories. If you wish to self-archive your article, please use the accepted manuscript version for posting on your own website. You may further deposit the accepted manuscript version in any repository, provided it is only made publicly available 12 months after official publication or later and provided acknowledgement is given to the original source of publication and a link is inserted to the published article on Springer's website. The link must be accompanied by the following text: "The final publication is available at link.springer.com". 


\title{
A Review of the Literature on Fuel Poverty with a Focus on Ireland
}

\author{
Graeme O’Meara'
}

Accepted: 1 July 2015

(c) Springer Science+Business Media Dordrecht 2015

\begin{abstract}
Fuel poverty has become a more prescient issue in recent years, both due to harsher winters and the economic downturn, which has made heating the home more difficult for many. Fuel poverty is sensitive to energy prices and also has a capital component linked to the energy efficiency of the home and its appliances. In 2013, $16 \%$ of Irish individuals were recorded as being deprived of heating in the previous year, while $10 \%$ were recorded as being unable to keep the home adequately warm. The data shows that fuel poverty has increased markedly since 2009. In this article, we review the literature on fuel poverty including the definition and measurement of fuel poverty, as well as the impacts on health and well-being. We also examine current policy initiatives aimed at alleviating fuel poverty and this is undertaken with a special focus on Ireland.
\end{abstract}

Keywords Fuel poverty $\cdot$ Health $\cdot$ Welfare $\cdot$ Public policy

\section{Introduction}

Fuel poverty has become a more prescient issue in Ireland in recent years, both due to more harsh winters and the economic downturn, which has made heating the home more difficult for many. Fuel poverty is both sensitive to energy prices and also has a capital component linked to the energy efficiency of the home and its appliances. Aside from being a form of discomfort and deprivation, it also has health implications, particularly for children (Liddell and Morris 2010; Institute for Public Health in Ireland (IPH) 2009).

There are a number of negative impacts of fuel poverty. Colder indoor temperatures place thermal stress on the body, affecting the immune system and the blood and cardiovascular system. Houses that are cold and damp tend to generate mould and dust mites that further intensify respiratory and allergic conditions. The indirect effects of fuel

Graeme O’Meara

graeme.o-meara@ucdconnect.ie

1 University College Dublin, Belfield, Dublin 4, Ireland 
poverty include material deprivation as a result of affordability issues related to the cost of heating the home, where occupants may have to cut back on other areas of spending, leading to social exclusion. High energy costs may also lead to the accumulation of debt to pay bills and spatial shrink as only some areas of the house can be heated.

Based on data from the Survey on Income and Living Conditions (SILC), the percentage of individuals in Ireland "without heating at some stage in the last year" and "unable to afford to keep the home adequately warm" remained relatively constant between 2003 and 2009, before increasing markedly between 2010 and 2013. The percentage of individuals "without heating" was at an all time high of $16 \%$ in 2013, while those "unable to afford warmth" was also at an all time high of $10 \%$ in the same year. In 2012, $10.8 \%$ of the total European population were unable to keep their home adequately warm, increasing to $24.4 \%$ when referring to low-income people (BPIE 2014).

In this article, we review the literature on fuel poverty including the definition and measurement of fuel poverty, as well as the impacts on health and well being. We also examine current policy initiatives aimed at alleviating fuel poverty and this is undertaken with a special focus on Ireland.

\section{Defining Fuel Poverty}

Fuel poverty is broadly defined as an inability to afford an acceptable level of warmth in the home. As described by Boardman (2010: 256), it is the phenomenon whereby a household struggles to "afford adequate services... clearly demonstrated when the home is cold or fuel debts accumulate." Fuel poverty is driven by three principal factors including the cost of energy and hence heating the home, the income levels of the household and the level of fuel efficiency of the dwelling (Fig. 1). The most vulnerable groups to fuel poverty include the elderly, the disabled, young children, single parents, and persons with low incomes. Fuel poverty is more widespread among low income households that may not be able to afford the cost of heating the home, particularly when energy prices are high and rising, and when the dwelling structure is poorly insulated, leading to low levels of fuel efficiency and thereby higher energy costs. Previous research has suggested several reasons for this: firstly, many low income households rent their dwelling and hence where occupants are tenants, they lack any incentives to invest in household energy efficiency; second, low income households have more limited access to credit (e.g. for thermal improvements to the dwelling); and third, often low income households do not invest in thermal improvements due to imperfections in the supply and use of information about efficiency opportunities and schemes (Scott et al. 2008).

However, recent research by Watson and Maitre (2015) for Ireland showed that the relationship between housing variables (including dwelling type, dwelling age and housing quality problems) and fuel poverty was not significantly different from the relationship between housing variables and basic deprivation. The results suggested that fuel poverty is a primarily a problem of inadequate resources rather than a housing quality issue, and it was found that individuals in detached houses (which would cost more to heat) were less likely to be fuel poor than those in semi-detached or terraced housing. The authors conclude that command over resources (i.e. income and savings) rather than the cost of heating the dwelling or energy efficiency of the dwelling is the key driver of fuel poverty.

Fuel poverty is measured in the UK using the BREDEM-12 algorithm that calculates the cost of heating a home, and takes into account household income, the current cost of heating fuel and the energy efficiency of the house. Households are classified as being in 
Fig. 1 Key drivers of fuel poverty

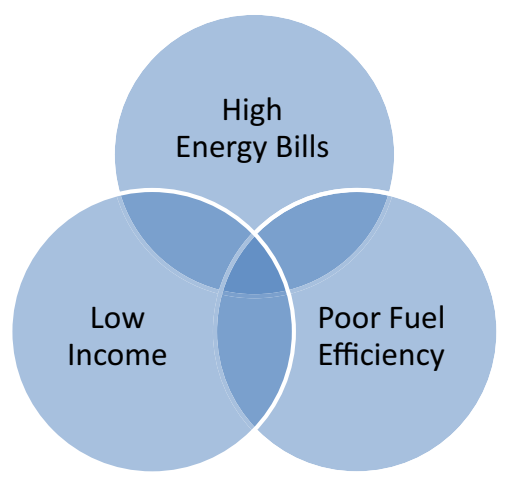

fuel poverty when they require $10 \%$ or more of their income to achieve WHO standards $\left(21{ }^{\circ} \mathrm{C}\right.$ in living rooms and $18{ }^{\circ} \mathrm{C}$ in all other rooms). This definition comes from Boardman (1991) and the emphasis is on fuel costs required to achieve either a minimum heating regime to safeguard health or a standard regime to provide thermal comfort plus adequate lighting, cooking and typical appliance use. In the United States, fuel poverty is given the term 'energy insecurity' and 20 other OECD countries describe it as 'lacking affordable warmth' which is measured through household surveys asking questions such as how often heating is foregone on cold days, whether other needs are left unfulfilled in order to heat the home, and whether debt has been incurred due to inability to pay energy bills. In $2012,10.8 \%$ of the total European population were unable to keep their home adequately warm, increasing to $24.4 \%$ when referring to low-income people (BPIE 2014).

There are a number of negative impacts of fuel poverty. Colder indoor temperatures place thermal stress on the body, affecting the immune system and the blood and cardiovascular system. Houses that are cold and damp also generate mould and dust mites that further intensify respiratory and allergic conditions. Indirect effects of fuel poverty include material deprivation as a result of affordability issues related to the cost of heating the home, where occupants may have to cut back on other areas of spending, leading to social exclusion. High energy costs may also lead to the accumulation of debt to pay bills and spatial shrink as only some areas of the house can be heated. The most vulnerable groups to fuel poverty include the elderly, the disabled, young children, single parents, and persons with low incomes.

\subsection{Measuring Fuel Poverty}

While the concept of fuel poverty is relatively simple, its measurement is somewhat tedious. The literature points toward three widely applied measures of fuel poverty. The expenditure approach is based on the nominal amount that households spend on fuel and households are deemed to be fuel poor where they spend above a given percentage of their income on fuel costs. As discussed, this percentage is considered to be $10 \%$ of net income excluding housing costs, based on Boardman (1991). This approach is adopted in the Affordable Energy Strategy of the Irish Department of Communications, Energy and Natural Resources (DCENR 2011). Hills (2012) points out that it could exclude low income households that spend less than $10 \%$ of their income due to being unable to afford to spend more. Scott et al. (2008) gave an indicative estimate of the number of Irish households living in fuel poverty at $19.4 \%$ in 2008 based on the expenditure approach, and DCENR (2011) give an estimate of $21 \%$ based on a similar approach for 2009. 
A second measure of fuel poverty is to predict how much a household would have to spend on energy to achieve the temperatures recommended by the WHO. This is based on the dwelling, the costs of fuel and the household income. This method would avoid the conundrum above whereby a low income household spends less than $10 \%$ of their income due to being unable to afford to spend more because it looks at the amount they would need to spend and if this exceeds a certain level (Watson and Maître 2015). In the UK, the most recent definition of fuel poverty, a household is considered to be fuel poor where the required (predicted) fuel spending is above the median level for a household of that size and where spending the required amount left the household with remaining income below the poverty line (DECC 2013).

A third measure of fuel poverty is based on self report through survey analysis. Large scale social surveys such as the European Union (EU) Survey on Income and Living Conditions (SILC) include questions that elicit responses as to whether individuals surveyed have had to go without heating and whether they can afford to heat the home adequately. Subjective indicators such as survey responses can be more clear cut and avoid some of the uncertainty and complexities associated with other measures of fuel poverty.

Watson and Maître (2015) note that an issue with many indicators of fuel poverty is that often households with high incomes can report fuel poverty and this is across both the expenditure and self report approach. For example, high income households may not be able to afford adequate heating due to other constraints on income such as health costs, accumulated debt, and high household running costs. In addition, in responding to surveys households may factor in changes in expected or future income as well as current income.

\section{Health Implications of Fuel Poverty}

The World Health Organisation (WHO) recommends a minimum indoor temperature of $21{ }^{\circ} \mathrm{C}$ in living rooms and $18{ }^{\circ} \mathrm{C}$ in all other rooms. A temperature below the levels recommended by the WHO may spur negative health implications. There are significant effects on the health of households living in fuel poverty, particularly in terms of respiratory illnesses such as asthma, as well as mental health and susceptibility to illness.

The main health issues associated with fuel poverty are changes in blood pressure and blood chemistry during cold weather, which can increase the risk of catastrophic cardiovascular or cerebrovascular events such as strokes, myocardial infarctions or pulmonary embolisms. Damp and cold conditions can also suppress the immune system increasing the risk of infections, pneumonia, asthma, arthritis, hypothermia, respiratory illnesses and psychological effects. Hypothermia is a medical emergency defined as a body temperature lower than $35{ }^{\circ} \mathrm{C}$ due to prolonged exposure to ambient cold temperatures without appropriate protection. (Romero-Ortuno et al. 2013) In Ireland, winters tend to be cool and air temperatures inland are about $6-8{ }^{\circ} \mathrm{C}$ during wintertime and they reach $16-18{ }^{\circ} \mathrm{C}$ during summer days. (Romero-Ortuno et al. 2013) In general, it is difficult to assert that any one of these temperatures is attributable to fuel poverty, as they can be related to the particular circumstances and health of the individual, and aggravated rather than induced by fuel poverty.

\subsection{Hypothermia}

Romero-Ortuno et al. (2013) find that the Irish National Deprivation Index (NDI), which measures material deprivation, could be an adequate tool to target fuel poverty in older people. Using the St. James' Hospital patients database, they survey all community 
dwelling patients (i.e. not in a nursing home) aged 65 or over and select those with hypothermia to compare with those without hypothermia. The study shows that a readily available measure of material deprivation increases when the weather is cold, and this raises the risk of admission with hypothermia. It showed that deprived older individuals may be vulnerable to hypothermia in winter, leading to increased morbidity and mortality. Further, they find that significant predictors of admission with hypothermia over the sample period (2002-2010 inclusive) were year of admission, air temperature on the day of admission and the NDI. Given that fuel poverty and material deprivation (measured by the NDI) are related to income, the NDI can be considered an adequate tool to target fuel poverty among the elderly. However, several caveats should be made: the air temperature on the day of admission data is based on recordings by Dun Laoghaire weather station, which could underestimate the inner city temperature extremes. Second, if the data were restricted to only the coldest months of the year, it would have accentuated the differences between the control and hypothermia groups.

\subsection{Other Health Conditions Affected by Fuel Poverty}

In general, a temperature of between $6-12{ }^{\circ} \mathrm{C}$ causes respiratory problems to become more common and raises cardiovascular risk. Exposure to between 6 and $12{ }^{\circ} \mathrm{C}$ for more than $2 \mathrm{~h}$ per day causes core body temperatures to drop, blood pressure to rise and increased risk of cardiovascular strain. (Baker 2001) Secondary hypothermia is low body temperature resulting from a medical illness lowering the temperature set point. It can cause decreased heat production, increased heat loss and impaired thermoregulation. Dust mites, a major contributor to asthma, are also related to low indoor temperatures, flourishing in $40 \%$ or more humidity and at temperatures of between 17 and $32{ }^{\circ} \mathrm{C}$. (Baker 2001) There are many health conditions that require high indoor temperatures, but many of these are temporary illnesses as opposed to long term medical conditions and it is hard to quantify the exact temperature required to prevent this condition from deteriorating. Chronic respiratory conditions like asthma or COPD do exacerbate in the cold, but other environmental factors such as humidity, pollutants, pollen etc. also play a role.

Going forward, it will be necessary to be able to quantify an exact medical complaint that is worthy of policy intervention to sustain a given indoor temperature. In addition, many households require all day heating because they are liable to be at home all day-e.g. older retired households, long term sick, unemployed etc. This illustrates another element of fuel poverty which is that certain groups are intrinsically more vulnerable to fuel poverty because their circumstances dictate greater consumption of fuel (Baker 2001).

\section{Studies on the Effects of Fuel Poverty}

Table 1 presents a summary of five large scale studies that have attempted to determine the effects of fuel poverty, taken from Liddell and Morris (2010: 2989).

The Warm Front study in England and Wales monitored retrofitted homes pre and post intervention and reported physical and mental health impacts. From this study, mortality effects were imputed (using data from other UK studies also) and it was found that heating and insulation improvements were associated with an average increase of 10 days to the life expectancy of men and 7 days to the life expectancy of women. The effects on mortality depended on whether individuals increased their indoor heating (by utilising appliances) after insulation: when they failed to increase their heating, mortality risk 


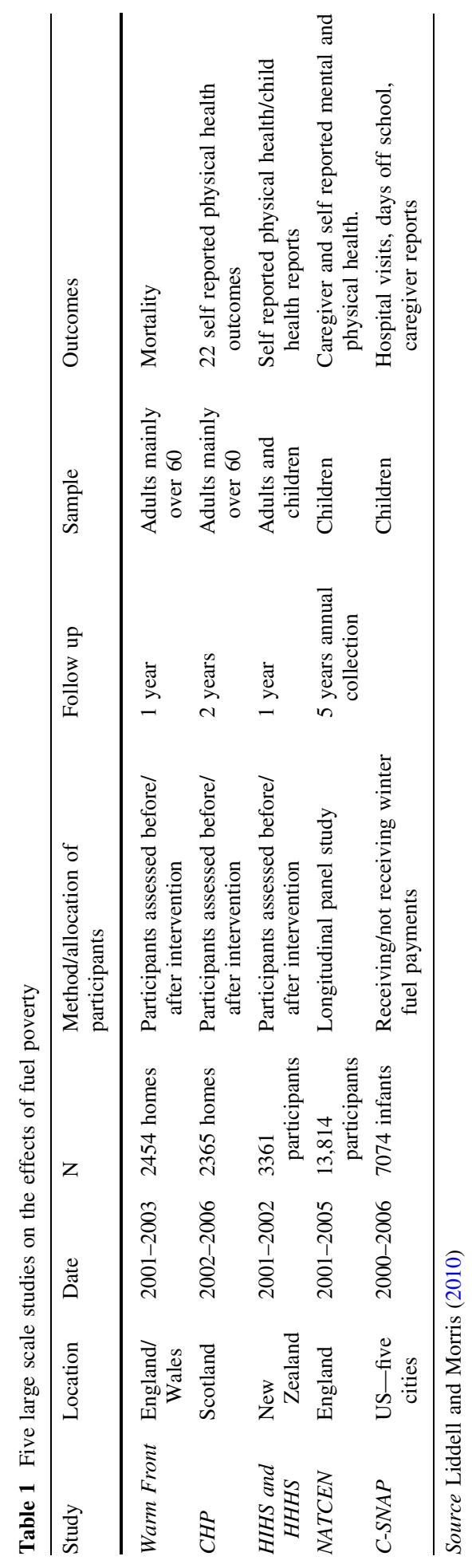


increased by $2.2 \%$ for every $1{ }^{\circ} \mathrm{C}$ fall in the outdoor temperature. The Warm Front study also reported that post intervention, warmer temperatures led to lower levels of anxiety and depression. Green and Gilbertson (2008) estimate that for every 10,000 properties (with two adults) improved by Warm Front, about 3000 occupants will be relieved of anxiety or depression. The interpretation is that if heating is more affordable, the relieved stress of paying for heating and incurring debts reduces the stress and anxiety. (Green and Gilbertson 2008) The Central Heating Programme in Scotland was conducted in a similar fashion to the Warm Front study.

The Housing, Insulation and Health Study (HIHS) and the Housing, Heat and Health Study (HHHS) in New Zealand first measured the effect of home insulation on adults and children, and second measured the effect of a home heating package for homes that had children with asthma and respiratory problems. The average daytime winter temperatures $\left(16{ }^{\circ} \mathrm{C}\right)$ in the retrofit region meant that homes required heating to meet the WHO standard. Despite no formal screening procedure, the sample largely comprised low income households living in wooden houses with no insulation and at least one resident per household with a respiratory health problem-which meant that the scheme was targeted towards households where there was a known health risk from living in cold and damp conditions. The first phase assessed all adults over the age of 11 and used criteria such as days off school, GP and hospital visits to gauge the effects of retrofitting. In the second phase, the emphasis was on homes with asthmatic children who had been supplied with home heating. Upon examining the survey, Howden-Chapman et al. (2007) find that there were $15 \%$ fewer days off school after retrofitting and this could be attributed to respiratory illnesses becoming less prominent once cold and damp conditions were eliminated.

The NATCEN (National Centre for Social Research) study in the UK and C-SNAP (Children's Sentinel Nutritional Assessment Programme) study in the US focussed specifically on the effects of cold and damp conditions on child and adolescent wellbeing, where $C$-SNAP compared infant development in low income households which either received or did not receive a winter fuel supplement, and used a four item home energy security indicator to explore the extent to which homes had foregone heating in the past year. NATCEN found that $15 \%$ of children who lived at least 3 years in cold and damp homes had respiratory problems, compared with $6 \%$ who had never lived in such conditions. When other factors such as mother's education, ethnicity, employment and marital status were accounted for, the $C$-SNAP study reported that children under 3 years from low income families who received a winter fuel subsidy had significantly higher weight for their age and lower nutritional risk for depressed growth compared to those children from homes without a fuel subsidy. As infancy is a period of rapid growth and high calorific need, infants living in cooler homes require more calories than average and C-SNAP suggested that children in homes without a winter fuel subsidy consumed fewer calories than subsidised infants. This is in tandem with research by the USA National Health and Nutrition Examination Survey that showed that drops in temperature caused households to cut back on food expenditures in which low income households decreased calorie intake in adults by 147 calories per day and in children by 147 calories per day. Liddell and Morris (2010) refer to studies in which early living conditions remain predictive of health risk in later life, even after other concurrent and subsequent life experiences (social and economic) are accounted for. With respect to mental health affects, the NATCEN study showed that $28 \%$ adolescents who lived for long periods in homes that lacked affordable warmth were classified as having multiple mental health risks, compared to $4 \%$ who had always lived in homes that had affordable warmth. (Barnes et al. 2008 When broken into specific symptoms-13\% truanted, $10 \%$ were expelled or excluded from school and $7 \%$ 
were in trouble with the police. This could be attributed to problems such as spatial shrink and crowding.

Healy and Clinch (2002) surveyed 1500 households, inquiring about temperatures on a room-to-room basis, with a particular focus on temperatures during the winter. The sample was split into fuel poor (those who declared so) and non fuel poor and respondents rated their level of thermal comfort on a scale of one to seven with seven being very comfortable. It was found that about one in seven Irish households (14\%) and almost three in ten fuel poor households contain living rooms below the WHO standard. About $50 \%$ of elderly households failed to achieve the minimum temperature of at least $20{ }^{\circ} \mathrm{C}$ to avoid cold strain and $16.1 \%$ of households over 65 had living rooms less than $18{ }^{\circ} \mathrm{C}$. Further, upon disaggregating the data by class, households on low incomes were less likely to reach the $18{ }^{\circ} \mathrm{C}$ minimum temperature and households with more dependents exhibited the highest incidence of cold living room temperatures. The highest incidence of fuel poverty was among lone elderly respondents and fuel poverty was less prevalent among married respondents. One must bear in that these statistics are somewhat out of date and there have been significant economic developments since this survey was conducted. However, the policy implications are quite clear: fuel poverty impacts the public health and poor energy efficiency increases energy consumption and emissions, such that policies aimed at improving the thermal efficiency of the Irish housing stock and encouraging retrofitting to households would tend to reduce these problems. Potential biases contained in the studies could be the inclusion of individuals without any health risk and the exclusion of individuals with a health risk related to fuel poverty. Contamination found in the HIHS and HHHS studies (New Zealand) was the problem of thermal resisters where some individuals retain low indoor temperatures after insulation. In the Warm Front study, $25 \%$ of homes had temperatures $2{ }^{\circ} \mathrm{C}$ below the WHO standard, while in New Zealand $16 \%$ elected not to increase temperatures. Thus, the effects of making a home more energy efficient will depend on the baseline levels of energy efficiency and thermal comfort, the scale of efficiency improvements, and whether retrofitted households 'choose' to increase their heating. It is hard to quantify the benefits of insulation and attempts at tackling fuel poverty as gains are typically in individuals' perceptions of wellbeing. The studies show demonstrable improvements in the health of young people in terms of infants' weight gain, days off school, hospital admission rates etc.

\section{The Prevalence of Fuel Poverty in Ireland}

In looking at the prevalence of fuel poverty in Ireland, one of the most readily available means is based on a comprehensive survey on the social profile of households. The Survey on Income and Living Conditions (SILC) is part of a European Union project to provide a harmonised dataset on the income and living conditions of households. The central statistics office administer the survey in Ireland and the data is used to monitor poverty and social inclusion, and encompasses a wide range of questions on socio-demographics of household members, including income, personal characteristics, health, education, employment status, labour market position and living conditions. It also provides a number of poverty indicators including at risk of poverty rate, the consistent poverty rate and rates of enforced deprivation. ${ }^{1}$ The data is available from 2003 to 2013, the latter of which is the year for which the latest data is available. The sample size varies by year from 8000 to 15,000 individuals and between 4000 and 6000 households. It has become conventional to

${ }^{1}$ http://www.cso.ie/en/silc/aboutthesilc/. 
analyse poverty and deprivation at the level of the individual even though many of the indicators are captured at the household level (Eurostat 2010; Watson and Maître 2015).

Three questions in the SILC data can be used to provide an indication of the frequency of fuel poverty. These include: ${ }^{2}$

- Without Heating at Some Stage in the Last Year have you ever had to go without heating during the last 12 months through lack of money? (I mean have you had to go without a fire on a cold day, or go to bed to keep warm or light the fire late because of lack of coal/fuel?) (yes/no).

- Unable to Afford to Keep the Home Adequately Warm does the household keep the home adequately warm? (if no, is it because the household cannot afford to or is there another reason?) (yes/no because cannot afford/no other reason).

- Utility Arrears in the last 12 months, did it happen that the household was unable to pay utility bills (heating, electricity, gas, refuse collection) for the main dwelling on time, due to financial difficulties? Telephone bills should NOT be considered as utility bills. (yes/no/not applicable as the household doesn't have any utility bills).

Among the other deprivation questions include: does your household have a roast joint (or its equivalent) once a week? Does the household have family or friends for a drink or a meal once a month? And does each household member possess two pairs of strong shoes?

In 2013, more than $30 \%$ of the Irish population experienced at least two types of enforced deprivation, and this compares with $27 \%$ in 2012 and a 7 year low of $12 \%$ in 2007. ${ }^{3}$ In Fig. 2, we plot the frequency of fuel poverty since 2003. In general, the percentage of individuals "without heating at some stage in the last year" and "unable to afford to keep the home adequately warm" remained relatively constant between 2003 and 2009, before increasing markedly between 2010 and 2013. The percentage in arrears of utility bills has also increased substantially since 2008 and was close to $18 \%$ in 2013. The percentage of individuals "without heating" was at an all time high of $15.7 \%$, while those "unable to afford warmth" was also at an all time high of $10 \%$ in 2013. When we examine the numbers of individuals that reported any of these issues (i.e. reported either one or more), we find that the numbers rise dramatically from 2008 onwards, rising from 10.5 to $26.5 \%$, a $152 \%$ increase. ${ }^{4}$ These findings suggest that the prevalence of fuel poverty has become more widespread and is increasing.

It is important to recall that in 2008 the Irish economy fell into a deep recession with unemployment rising from $6.4 \%$ in 2008 to $13.1 \%$ in $2013 .{ }^{5}$ Thus, falls in income were likely to be driving this inability to keep the home adequately warm and forego heating during the year.

In Fig. 3, we look at the prevalence of fuel poverty among individuals who are at risk of poverty, defined as those individuals living on $60 \%$ of the median income threshold (including all social transfers). The percentage of individuals at risk of poverty who may be living in fuel poverty is significantly higher than those not at risk of poverty (Fig. 4). In 2013, $31 \%$ of individuals went without heating during the last year, while $19 \%$ were

\footnotetext{
${ }^{2}$ http://www.cso.ie/en/media/csoie/eusilc/documents/SILCmanual2013.pdf.

${ }^{3}$ http://www.cso.ie/en/releasesandpublications/er/silc/surveyonincomeandlivingconditions2013/\#.VaE8_ MZVhHx.

4 The percentages for 2008 and 2011 are lower than the percentages presented in Scott et al. (2008) and DCENR (2011) using the expenditure approach.

${ }^{5}$ http://www.cso.ie/multiquicktables/quickTables.aspx?id=lrm03_lra03.
} 


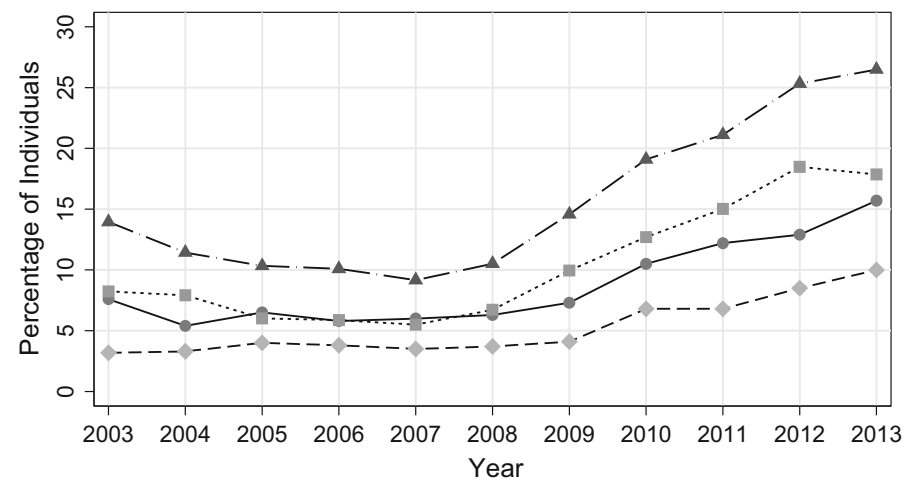

Without heating at some stage in the last year
$\ldots-$ - Unable to afford to keep the home adequately warm
$\ldots$

Fig. 2 Percentage of individuals experiencing fuel poverty 2003-2013

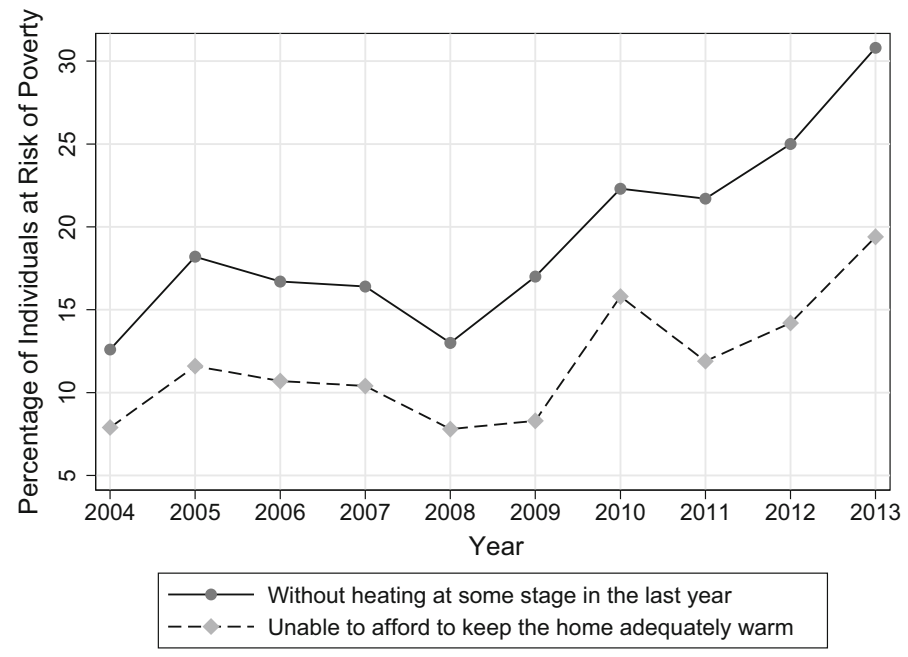

Fig. 3 Percentage of individuals at risk of poverty experiencing fuel poverty 2003-2013

unable to afford to keep the home adequately warm. The percentage of individuals "without heat" increased by $136 \%$ since 2009 and the percentage of individuals "unable to afford warmth" increased by $148 \%$ since 2008 . These percentages are a lot higher than for all individuals (Fig. 2) and this reflects the fact that these individuals may live in poverty. Further, the economic recession is likely to be a key factor unpinning the stark increase in the prevalence of fuel poverty among these individuals.

In Fig. 4, we show the corresponding survey results for individuals who are not at risk of poverty. Interestingly, the prevalence of fuel poverty among these people is more aligned with all individuals (Fig. 2), with $13 \%$ of individuals having gone without heating at some stage in the last year and $8 \%$ being unable to afford to keep the home adequately 


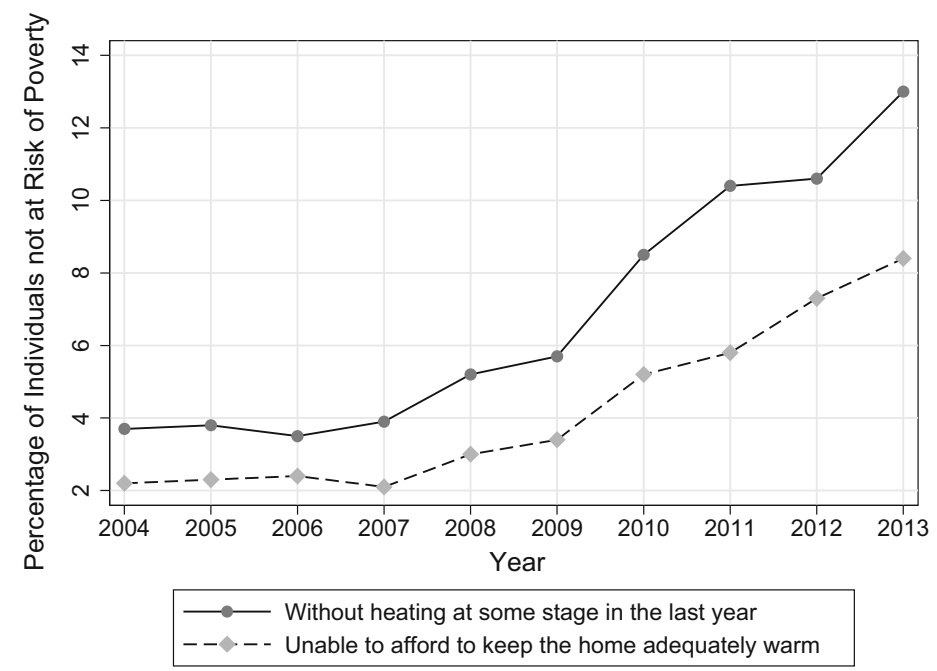

Fig. 4 Percentage of individuals not at risk of poverty experiencing fuel poverty 2003-2013

warm in 2013. Again, these percentages have risen substantially since 2008.

Taken together, these survey findings from the SILC data show that the prevalence of fuel poverty has risen substantially in recent years and has thus become a far more pressing issue from the perspective of anti poverty policies.

\section{Policy Initiatives to Alleviate Fuel Poverty}

Many countries have initiated policies to reduce fuel poverty through enhancing the energy efficiency and insulation quality of houses, both old and new. The UK Fuel Poverty Strategy - sets out targets for eliminating fuel poverty, with an overall target to eradicate fuel poverty by 2018 . The first phase, which ran from 2001 to 2010 , gave priority to three groups most vulnerable - those over 60, disability long term illness, families with children. The second phase (2010-2018) targets non vulnerable groups, and the strategy provides funding for improving the energy efficiency of housing stock, as well as encouraging progressively more stringent regulations that govern new buildings and retrofitting existing homes. In the US, there is national funding available for bill subsidies and energy conservation, as well as discounts, efficiency investments, pricing schemes and debt management. Under the Federal Weatherization Assistance Programme, homes to be weatherised are based on the occupants' energy costs rather than on their consumption, although these are likely to be related. The Low Income Home Energy Assistance Programme (LIHEAP) programme provides subsidies to suppliers of energy on behalf of eligible households and the majority goes to cold weather states.

\subsection{Policy in Ireland}

The policy response to fuel poverty in Ireland encompasses both short term initiatives in the form of fuel subsidies and long term initiatives in the form on investment in the thermal efficiency of the housing stock. McAvoy (2007) notes that the thermal efficiency of the 
Irish dwelling stock is amongst the lowest in Europe and this means difficulty for Ireland meeting its greenhouse emissions targets. The household sector accounts for $26 \%$ of total energy consumption and $29 \%$ of carbon dioxide emissions. Social Assistance schemes related to fuel poverty are operated through the Department of Social Protection. In addition to fuel related payments, social welfare policy relating to pensions, disability, carers, one parent families and unemployment have an important role to play in tackling fuel poverty. A number of key government policy documents outline the long term strategy for addressing fuel poverty:

- The National Action Plan for Social Inclusion sets out how the Government's social inclusion strategy will be achieved over the period 2007-2016. ${ }^{6}$ The plan identifies a number of high level strategic goals in certain key priority areas in order to achieve the overall objective of reducing consistent poverty. Among the areas where the plan focuses its attention includes provision of "the type of supports that enable older people to maintain a comfortable and high-quality standard of living", and "building viable and sustainable communities, improving the lives of people living in disadvantaged areas and building social capital". These areas include addressing the challenge of energy poverty.

- Delivering a Sustainable Energy Future for Ireland is the Government's energy policy framework for the period 2007-2020. Strategic Goal 5 within the White Paper in particular enunciates the Government's policy in the area of affordable energy in stating that everyone should be able to afford an adequate energy supply and to live in a warm home. ${ }^{7}$

- Maximising Ireland's Energy Efficiency-National Energy Efficiency Action Plan, 2009-2020 ${ }^{8}$ sets out policies and measures that have the potential to contribute towards achieving Ireland's national target for a $20 \%$ reduction in energy demand across the whole of the economy by 2020. The plan sets out a vision where "all new Irish housing will be carbon neutral" and that "efficiency standards in older homes will be significantly improved through retrofitting actions".

The Affordable Energy Strategy (DCENR 2011), ${ }^{10}$ a cross departmental initiative involving the Departments of Communications, Energy and Natural Resources, Public Expenditure and Reform, the Taoiseach, the Environment, Community and Local Government, Social Protection, Health, and Children, in addition to the Commission for Energy Regulation, SEAI, ESB Electric Ireland, the Institute of Public Health in Ireland, the Energy Poverty Coalition and Bord Gáis, aims to:

- Improve the thermal efficiency of low income homes;

- Undertake a partnership approach in tackling fuel poverty by collaborating across departments and with a range of stakeholders

- Deliver cost effective approaches to addressing fuel poverty

- Be consistent with the government's wider climate change policy and thereby benefit the environment.

\footnotetext{
${ }^{6}$ National Action Plan for Social Inclusion, 2007-2016. Government Publications Office Dublin, February 2007, or via: http://www.socialinclusion.ie/documents/NAPinclusionReportPDF.pdf.

${ }^{7}$ Delivery a Sustainable Energy Future for Ireland-Energy Policy Framework 2007-2020. Government White Paper. Department of Communications, Energy and Natural Resources. See: www.dcenr.gov.ie.

${ }^{8}$ Maximising Ireland's Energy Efficiency-National Energy Efficiency Action Plan, 2009-2020. Department of Communications, Energy and Natural Resources. May 2009. See: www.dcenr.gov.ie.

${ }^{9}$ Ibid. Page 75.

${ }^{10}$ http://www.dcenr.gov.ie/NR/rdonlyres/53F3AC25-22F8-4E94-AB73-352F417971D7/0/AffordableEnergy StrategyFINAL.pdf.
} 
The Government's Affordable Energy Strategy identified a person as experiencing energy poverty if they spent more than $10 \%$ of their income on energy costs, with a person said to be in severe energy poverty if the figure was above $15 \%$ and extreme energy poverty defined as occurring if the figure was above $20 \%$. Under these definitions it was estimated that approximately $20 \%$ of all households, experienced energy poverty in Ireland in 2009 with 151,000 households experiencing severe energy poverty and 83,000 households experiencing extreme energy poverty.

\subsection{Short Term Initiatives}

The social welfare system, administered by the Department of Social Protection (DSP), plays an important role in seeking to alleviate the impacts on families and individuals arising from various forms of poverty and social exclusion.

While no scheme exists which is directed explicitly at the energy poor, a number of schemes and programmes operate with the primary objectives of providing income support to families and individuals to assist in meeting the costs of household energy/fuel needs.

Specifically, the Government is currently providing energy/fuel cost-related supports under the following DSP-administered schemes:

- The National Fuel Allowance;

- The Electricity and natural gas allowances under the Household Benefits Package; and

- The Heating Supplement under the Supplementary Welfare Allowance Scheme.

\subsubsection{National Fuel Scheme}

The objective of the National Fuel Allowance (NFA) is to assist householders on long-term social welfare or Health Services Executive payments with meeting the additional cost of their heating needs during the winter season.

The NFA is means tested and involves a basic cash payment, currently set at $€ 20$ per week, to eligible households for a 32 week period from October to April each year. ${ }^{11}$

It is estimated that a total of 413,817 households were in receipt of the fuel allowance in 2014, costing an estimated $€ 208 \mathrm{~m}$ (DCENR 2015: 15). ${ }^{12}$

One of the benefits of the scheme is that it provides a cash-based payment, meaning that households can choose to use the assistance in the manner best suited to their needs, e.g. for different fuels such as electricity, heating oil, peat-based products etc.

\subsubsection{Household Benefits Package}

Under the Household Benefits Package, qualifying households may choose between either an Electricity Allowance or a Gas Allowance.

The Electricity Allowance is a $€ 35$ cash credit that is paid each month to a qualifying household. The allowances are available regardless of electricity supplier but customers have the option of having the credit automatically applied to the bill if the recipient is an Electric

\footnotetext{
${ }^{11}$ Further details on the National Fuel Allowance scheme, including eligibility criteria, can be found at: http://www.welfare.ie/en/Pages/820_National-Fuel-Scheme.aspx.

12 Towards a New Affordable Energy Strategy for Ireland, Department of Communications, Energy and Natural Resources, January 2015. http://www.dcenr.gov.ie/NR/rdonlyres/1045379C-F07C-4D78-BFE17674FA3AFF67/0/AffordableEnergyConsultationPaper.pdf.
} 
Ireland customer. If the electricity provider is not Electric Ireland, or if the recipient opts for it, the allowance is paid directly to the recipient. ${ }^{13}$ Approximately 364,230 households benefitted from the electricity allowance in 2014 at a cost of $€ 153.2 \mathrm{~m}$ (DCENR 2015: 15). ${ }^{14}$

The Natural Gas Allowance works in a similar manner to the Electricity Allowance with a $€ 35$ cash sum with the option to receive the allowance credited onto a bill if they are with BGE or Flogas. Approximately 45,095 households benefitted from the Electricity Allowance in 2014 at a cost of $€ 20 \mathrm{~m}$ (DCENR 2015: 15). ${ }^{15}$

The Household Benefits Package is available to all persons over 70 years of age but is also available to certain groups that meet the criteria. For persons aged between 66 and 70 , they can receive the benefits package of they are in receipt of the state pension and they live alone. For persons under 66, they must be in receipt of a qualifying payment and live alone.

\subsubsection{Heating Supplement Under the Supplementary Welfare Allowance Scheme}

In addition to the basic supports available under the National Fuel Allowance and the Household Benefits Package, under the DSP's Supplementary Welfare Allowance Scheme, a Community Welfare Office within the Health Service Executive may also provide a special heating supplement for people who have an exceptional heating need by virtue of a health condition or medical need. ${ }^{16}$

In Ireland the social assistance schemes operated under the National Fuel Scheme and Household Benefits Package have sought to be responsive to the issue of rising fuel prices. While supplementing incomes of poor is important, putting warmth into thermally inefficient homes is ultimately a bad long term investment. Capital investment in our poor housing stock and improving thermal efficiency must form the backbone of any strategic approach to tackling fuel poverty on this island. Building regulations need standards of thermal efficiency that are high enough to deliver real change, both in terms of the reduction of fuel poverty and in their contribution to conservation of the broader environment.

\subsection{Long Term Initiatives}

A number of long term initiatives aimed at improving the thermal efficiency of the housing stock are also in place.

\subsubsection{Better Energy Warmer Homes (BEWH)}

The Better Energy Warmer Homes (BEWH) scheme was launched in April 2008. The scheme is national in scope and is administered by SEAI. Groups eligible for the scheme include owner occupied homes (non Local Authority) constructed before 2006 and the

\footnotetext{
13 Ibid.

14 Ibid.

15 Ibid.

16 The Supplementary Welfare Allowance (SWA) Scheme came into operation on 1 July 1977. It was introduced to replace the home assistance service for persons whose means are insufficient to meet their needs and those of their dependants. SWA can consist of a basic payment and/or a supplement in respect of certain expenses a person may not be able to meet. In order to qualify for a heating supplement the claimant must live alone or only with a qualified adult or child/children and must have exceptional heating needs due to ill-health or infirmity. See: http://www.welfare.ie/EN/OperationalGuidelines/pages/swa.aspx.
} 
owner is in receipt of some form of social welfare payment including the Fuel Allowance, jobseekers allowance or family income supplement. Energy efficiency upgrades are delivered through regional community based organisations.

The scheme provides grants to homeowners of dwellings to invest in energy efficiency improvements in one or more of the following types of works covered under the scheme: ${ }^{17}$

- Attic insulation

- Draught proofing

- Lagging jackets

- CFL bulbs

- Cavity wall insulation (only in certain parts of the country)

Grant levels are fixed for each type of measure, currently ranging between $€ 300$ for roof insulation and up to $€ 4500$ for external wall insulation. ${ }^{18}$

By the end of 2014, the scheme had upgraded more than 112,000 energy poor homes since its commencement, with an overall spend of almost $€ 137$ million (DCENR 2015: 9). ${ }^{19}$

\subsubsection{DEHLG and Local Authority Schemes}

In addition to SEAI-administered schemes, a number of energy efficiency assistance schemes are also operated via the Department of the Environment, Heritage and Local Government (DEHLG) and the Local Authorities. These include:

- Housing Aid for Older People

- Local Authority energy efficiency retrofit programme

- Central heating programme

The Housing Aid for Older People scheme is a retrofitting scheme administered by local authorities. ${ }^{20}$ The scheme is available to older people (generally aged over 66 years), who require necessary repairs or improvements to their homes. It is means-tested, with a maximum grant available of up to $€ 8000$, to cover up to $95 \%$ of the cost of works. Types of works assisted under the scheme include structural repairs or improvements; re-wiring; dry-lining; repairs to/ replacement of windows and doors; provision of central heating, water and sanitary services; contract-cleaning; and painting and radon remediation works. In 2014, 3634 payments were made at a total cost of $€ 13,497,762$, and more than 24,000 homes benefitted since 2010 . $^{21}$

The Local Authority energy efficiency retrofit programme was introduced in 2009. More than 13,000 homes benefitted in $2013 .^{22}$ Activity under the programme is targeted at both

\footnotetext{
${ }^{17}$ For the upgrades to be eligible for the grant, certain standards must be met. For example, it is necessary for any upgraded boiler to be of at least $90 \%$ efficiency. In addition, landlords and owners of multiple properties may also apply, however they must submit a separate application form for each property. A SEAIregistered/approved contractor must complete works.

18 http://www.seai.ie/Grants/Better_energy_homes/Better-Energy-Homes-Leaflet-2015.pdf.

19 Towards a New Affordable Energy Strategy for Ireland, Department of Communications, Energy and Natural Resources, January 2015. http://www.dcenr.gov.ie/NR/rdonlyres/1045379C-F07C-4D78-BFE17674FA3AFF67/0/AffordableEnergyConsultationPaper.pdf.

${ }^{20}$ http://www.citizensinformation.ie/en/housing/housing_grants_and_schemes/housing_aid_for_older_ persons_scheme.html.

21 Towards a New Affordable Energy Strategy for Ireland, Department of Communications, Energy and Natural Resources, January 2015. http://www.dcenr.gov.ie/NR/rdonlyres/1045379C-F07C-4D78-BFE17674FA3AFF67/0/AffordableEnergyConsultationPaper.pdf.

22 http://www.environ.ie/en/DevelopmentHousing/Housing/News/MainBody,35756,en.htm.
} 
vacant properties, where access can be gained quickly and works completed without delay, and local authority apartment complexes where the nature of the works will not require tenant relocation.

The Central heating programme was introduced in July 2004 to support installation of central heating in existing local authority rented dwellings. ${ }^{23}$ Each Local Authority administers it locally. Grant support to a maximum of $€ 6000$ or up to $80 \%$ of the cost is available (whichever is the lesser), with the balance of cost met by the housing authority. In addition to central heating facilities the work may also include related energy improvement and smoke detection measures.

\section{Summary and Conclusions}

This article has reviewed the literature on fuel poverty including the measurement and the impacts on health and well being, as well as the current policy stance in Ireland.

Fuel poverty is driven by three principal factors including the cost of energy and hence heating the home, the income levels of the household and the level of fuel efficiency of the dwelling. Fuel poverty is more rampant among low income households that perhaps cannot afford the cost of heating the home, when energy prices are high and rising, and when the dwelling structure is poorly insulated, leading to low levels of fuel efficiency and thereby higher energy costs.

The World Health Organisation (WHO) recommends a minimum indoor temperature of $21{ }^{\circ} \mathrm{C}$ in living rooms and $18{ }^{\circ} \mathrm{C}$ in all other rooms. Households are classified as being in fuel poverty when they require $10 \%$ or more of their income to achieve WHO standards. This definition comes from Boardman (1991) and the emphasis is on fuel costs required to achieve either a minimum heating regime to safeguard health or a standard regime to provide thermal comfort plus adequate lighting, cooking and typical appliance use. In 2012, $10.8 \%$ of the total European population were unable to keep their home adequately warm, increasing to $24.4 \%$ when referring to low-income people (BPIE 2014).

The literature points toward three widely applied measures of fuel poverty. The expenditure approach is based on the nominal amount that households spend on fuel and households are deemed to be fuel poor where they spend above a given percentage of their income on fuel costs.

A second measure of fuel poverty is to predict how much a household would have to spend on energy to achieve the temperatures recommended by the WHO. This is based on the dwelling, the costs of fuel and the household income.

A third measure of fuel poverty is based on self-report through survey analysis. Largescale social surveys such as the European Union (EU) Survey on Income and Living Conditions (SILC) include questions that elicit responses as to whether individuals surveyed have had to go without heating and whether they can afford to heat the home adequately.

A temperature below the levels recommended by the WHO may spur negative health implications. There are significant effects on the health of households living in fuel poverty, particularly in terms of respiratory illnesses such as asthma, as well as mental health and susceptibility to illness. The main health issues associated with fuel poverty are

23 http://www.environ.ie/en/DevelopmentHousing/Housing/SocialHousingSupport/CentralHeating Programme/. 
changes in blood pressure and blood chemistry during cold weather, which can increase the risk of catastrophic cardiovascular or cerebrovascular events such as strokes, myocardial infarctions or pulmonary embolisms. Damp and cold conditions can also suppress the immune system increasing the risk of infections, pneumonia, asthma, arthritis, hypothermia, respiratory illnesses and psychological effects. Hypothermia is a medical emergency defined as a body temperature lower than $35{ }^{\circ} \mathrm{C}$ due to prolonged exposure to ambient cold temperatures without appropriate protection (Romero-Ortuno et al. 2013).

In general, a temperature of between $6-12{ }^{\circ} \mathrm{C}$ causes respiratory problems to become more common and raises cardiovascular risk. Exposure to between 6 and $12{ }^{\circ} \mathrm{C}$ for more than $2 \mathrm{~h}$ per day causes core body temperatures to drop, blood pressure to rise and increased risk of cardiovascular strain. (Baker 2001) Dust mites, a major contributor to asthma, are also related to low indoor temperatures, flourishing in $40 \%$ or more humidity and at temperatures of between 17 and $32{ }^{\circ} \mathrm{C}$. (Baker 2001) There are many health conditions that require high indoor temperatures, but many of these are temporary illnesses as opposed to long-term medical conditions and it is hard to quantify the exact temperature required to prevent this condition from deteriorating.

A number of large-scale studies were undertaken to examine the effects of fuel poverty on health across a number of jurisdictions including the UK, the US and Ireland.

The Warm Front study in England and Wales monitored retrofitted homes pre and post intervention and reported physical and mental health impacts. It was found that heating and insulation improvements were associated with an average increase of 10 days to the life expectancy of men and 7 days to the life expectancy of women. The effects on mortality depended on whether individuals increased their indoor heating (by utilising appliances) after insulation: when they failed to increase their heating, mortality risk increased by $2.2 \%$ for every $1{ }^{\circ} \mathrm{C}$ fall in the outdoor temperature. The Warm Front study also reported that post intervention, warmer temperatures led to lower levels of anxiety and depression.

The National Centre for Social Research (NATCEN) study in the UK and Children's Sentinel Nutritional Assessment Programme (C-SNAP) study in the US focussed specifically on the effects of cold and damp conditions on child and adolescent wellbeing. NATCEN found that $15 \%$ of children who lived at least 3 years in cold and damp homes had respiratory problems, compared with $6 \%$ who had never lived in such conditions. When other factors such as mother's education, ethnicity, employment and marital status were accounted for, the $C$-SNAP study reported that children under 3 years from low income families who received a winter fuel subsidy had significantly higher weight for their age and lower nutritional risk for depressed growth compared to those children from homes without a fuel subsidy.

Healy and Clinch (2002) found that about one in seven Irish households (14\%) and almost three in ten fuel poor households contain living rooms below the WHO standard. Further, upon disaggregating the data by class, households on low incomes were less likely to reach the $18{ }^{\circ} \mathrm{C}$ minimum temperature and households with more dependents exhibited the highest incidence of cold living room temperatures. The highest incidence of fuel poverty was among lone elderly respondents and fuel poverty was less prevalent among married respondents.

In looking at the prevalence of fuel poverty in Ireland, we utilise data from the Survey on Income and Living Conditions (SILC). In general, the percentage of individuals "without heating at some stage in the last year" and "unable to afford to keep the home adequately warm" remained relatively constant between 2003 and 2009, before increasing markedly between 2010 and 2013. The percentage of individuals "without heating" was at 
an all-time high of $15.7 \%$, while those "unable to afford warmth" was also at an all-time high of $10 \%$ during 2013. When we examine the numbers of individuals that reported any of these issues (i.e. reported either one or more), we find that the numbers rise dramatically from 2008 onwards, rising from 10.5 to $26.5 \%$, a $152 \%$ increase. These findings suggest that the prevalence of fuel poverty has become more widespread and is increasing.

When we examine individuals who are at risk of poverty, we find that in 2013, $31 \%$ of individuals went without heating during the last year, while $19 \%$ were unable to afford to keep the home adequately warm. The percentage of individuals "without heat" increased by $81 \%$ since 2009 and the percentage of individuals "unable to afford warmth" increased by $133 \%$ since 2009 . These percentages are a lot higher than for all individuals and this reflects the fact that these individuals may live in poverty. Further, the economic recession is likely to be a key factor unpinning the stark increase in the prevalence of fuel poverty among these individuals.

The policy response to fuel poverty in Ireland encompasses both short term initiatives in the form of fuel subsidies and long term initiatives in the form of investment in the thermal efficiency of the housing stock.

The social welfare system, administered by the Department of Social Protection (DSP), plays an important role in seeking to alleviate the impacts on families and individuals arising from various forms of poverty and social exclusion. While no scheme exists which is directed explicitly at the energy poor, a number of schemes and programmes operate with the primary objectives of providing income support to families and individuals to assist in meeting the costs of household energy/fuel needs. These include the National Fuel Scheme, the Electricity and natural has allowances under the Household Benefits Package and the Heating Supplement under the Supplementary Welfare Allowance Scheme. In terms of long-term initiatives to target fuel poverty, the Better Energy Warmer Homes (BEWH) scheme and a number of local authority schemes aim to improve the thermal efficiency of homes.

In Ireland the social assistance schemes operated under the National Fuel Scheme and Household Benefits Package have sought to be responsive to the issue of rising fuel prices. While supplementing the benefits of the poor is a direct and effective means of targeting fuel poverty, putting warmth into thermally inefficient homes is ultimately a bad long-term investment. Thus, alleviating fuel poverty should have both a short term and long term element, where the long-term objective should be investing in the thermal efficiency of the housing stock. Building regulations should thus lay standards of thermal efficiency that will generate positive results for fuel poverty and the environment more generally.

\section{References}

Baker, W. (2001). Fuel poverty and ill health: A review. Bristol: Centre for Sustainable Energy. http://www. cse.org.uk/pdf/pub11.pdf.

Barnes, M., Butt, S., \& Tomaszewski, W. (2008). The dynamics of bad housing: the impact of bad housing on the living standards of children. London: National Centre for Social Research.

Boardman, B. (1991). Fuel poverty: From cold homes to affordable Warmth. London: Bellhaven Press.

Boardman, B. (2010). Fixing fuel poverty: Challenges and solutions. London: Earthscan.

Buildings Performance Institute Europe (BPIE) (2014). Alleviating fuel poverty in the EU. http://bpie.eu/ uploads/lib/document/attachment/60/BPIE_Fuel_Poverty_May2014.pdf.

Department of Communications, Energy and Natural Resources (DCENR) (2011). Warmer homes: A strategy for affordable energy in Ireland. http:/www.dcenr.gov.ie/NR/rdonlyres/53F3AC25-22F84E94-AB73-352F417971D7/0/AffordableEnergyStrategyFINAL.pdf. 
Department of Communications, Energy and Natural Resources (DCENR) (2015). Towards a new affordable energy strategy for Ireland. http://www.dcenr.gov.ie/NR/rdonlyres/1045379C-F07C-4D78BFE1-7674FA3AFF67/0/AffordableEnergyConsultationPaper.pdf.

Department of Energy and Climate Change (DECC) (2013). Annual Report on Fuel Poverty Statistics 2013. https://www.gov.uk/government/uploads/system/uploads/attachment_data/file/199833/Fuel_Poverty_ Report_2013_FINALv2.pdf.

Eurostat. (2010). Income poverty and material deprivation in European countries-Eurostat methodologies and working papers. Luxembourg: Eurostat.

Green, G., \& Gilbertson, J. (2008). Health impact evaluation of the warm front scheme. Sheffield Hallam University: Centre for Regional Social and Economic Research.

Healy, J. D., \& Clinch, J. P. (2002). Fuel poverty, thermal comfort and occupancy: results of a national household survey in Ireland. Applied Energy, 73, 329-343.

Hills, J. (2012). 'Getting the measure of fuel poverty: Final report of the fuel poverty review' London: Department of energy and climate change (DECC). http://sticerd.lse.ac.uk/dps/case/cr/CASEreport72. pdf.

Howden-Chapman, P., Matheson, A., Crane, J., Viggers, H., Cunningham, M., \& Blakely, T. (2007). Effect of insulating existing houses on health inequality: Cluster randomised study in the community. British Medical Journal, 334, 460-464.

Institute for Public Health in Ireland (IPH). (2009). Annual update on fuel poverty and health $2009 \mathrm{http} / /$ www.publichealth.ie/files/file/Annual $\% 20$ Update $\% 20$ on $\% 20$ Fuel $\% 20$ Poverty $\% 20$ and $\% 20 \mathrm{Health} \% 20$ 2009.pdf.

Liddell, C., \& Morris, C. (2010). Fuel poverty and human health: A review of recent evidence. Energy Policy, 38, 2987-2997.

McAvoy, H. (2007). All Ireland poverty paper on fuel poverty The Institute of Public Health in Ireland. http://lenus.ie/hse/bitstream/10147/45784/1/9138.pdf.

Romero-Ortuno, R., Tempany, M., Dennis, L., O'Riordan, D., \& Silke, B. (2013). Deprivation in cold weather increases the risk of hospital admission with hypothermia in older people. Irish Journal of Medical Science, 182, 513-518.

Scott, S., Lyons, S., Keane, C., McCarthy, D., \& Tol, R. J. (2008). 'Fuel poverty in Ireland: Extent, affected groups and policy issues' working paper 262, Dublin: Economic and Social Research Institute. https:// www.esri.ie/UserFiles/publications/20081110114951/WP262.pdf.

Watson, D., \& Maitre, B. (2015). 'Is fuel poverty in Ireland a distinct type of deprivation?' Economic and Social Review, 46(2), 267-291. 